\title{
Heaf Tuberculin Skin Test
}

National Cancer Institute

\section{Source}

National Cancer Institute. Heaf Tuberculin Skin Test. NCI Thesaurus. Code C85996.

A multiple puncture tuberculin skin test in which a Heaf gun (device containing 6 needles arranged in a circular pattern) is dipped into tuberculin purified protein derivative and pushed into the skin of the flexor surface of the left forearm. 